\title{
Fundamentals of MOF Thin Film Growth via Liquid-Phase Epitaxy: Investigating the Initiation of Deposition and the Influence of Temperature
}

\author{
Monica L. Ohnsorg, Christopher K. Beaudoin, and Mary E. Anderson* \\ Department of Chemistry, Hope College, 35 E. 12th Street, Holland, Michigan 49422, United States
}

Supporting Information

\begin{abstract}
Thin films can integrate the versatility and great potential found in the emerging field of metal-organic frameworks directly into device architectures. For fabrication of smart interfaces containing surface-anchored metal-organic frameworks, it is important to understand how the foundational layers form to create the interface between the underlying substrate and porous framework. Herein, the formation and morphology of the first ten cycles of film deposition are investigated for the wellstudied HKUST-1 system. Effects of processing variables, such as deposition temperature and substrate quality, are studied.

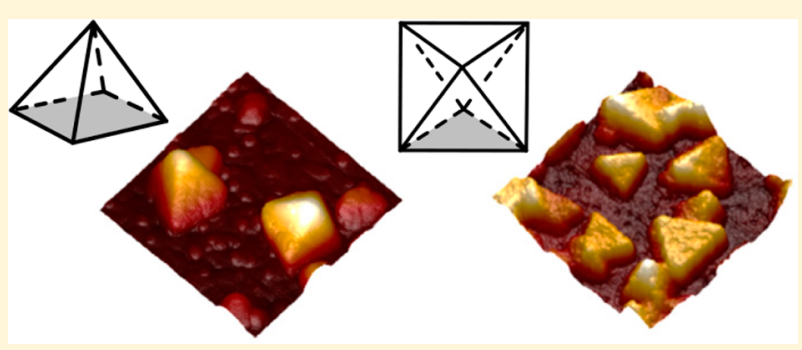
Sequences of scanning probe microscopy images collected after cycles of alternating solution-phase deposition reveal the formation of a discontinuous surface with nucleating and growing crystallites consistent with a Volmer-Weber growth mechanism. Quantitative image analysis determines surface roughness and surface coverage as a function of deposition cycles, producing insight regarding growth and structure of foundational film layers. For carboxylic acid terminated self-assembled monolayers on gold, preferred crystal orientation is influenced by deposition temperature with crystal growth along [100] observed at $25{ }^{\circ} \mathrm{C}$ and [111] favored at $50{ }^{\circ} \mathrm{C}$. This difference in crystal orientation results in reduced surface roughness and increased surface coverage at $50{ }^{\circ} \mathrm{C}$. To properly fabricate and fully determine the potential of this material for industrial applications, fundamental understanding of film formation is crucial.
\end{abstract}

\section{INTRODUCTION}

The incorporation of metal-organic frameworks (MOFs) directly within device architectures presents an exciting opportunity to employ the functionality of the material. MOFs are crystalline, porous materials with extremely high surface areas, exhibiting great potential for sensing, catalysis, and gas storage. ${ }^{1-9}$ Toward fabrication of smart interfaces harnessing the structural properties of MOF materials, it is crucial to understand how foundational layers form, connecting the underlying substrate to the porous framework. When thin nanoscale films are integrated into devices, it is, unfortunately, very common for defects in the film to negate or dominate the desired properties of the material. Surface-anchored metalorganic frameworks (SurMOFs) have been incorporated into structures such as low k-dielectric layers, photoelectrodes, and other smart interfaces. ${ }^{10-13}$ However, the nanostructure of these thin films has not been well characterized. The potential of this emerging nanomaterial may not be fully realized, in part, because of improper fabrication of the film due to a lack of fundamental understanding of how the film forms at the substrate interface. For self- and directed assembly of materials, it is common for defects to occur due to components becoming energetically trapped in undesirable conformations. For these assemblies to be assimilated in technological applications, methods for preventing, tolerating, and repairing these defects will be essential. Understanding the forces driving assembly will enable the quality of the SurMOF thin film to be improved.

Metal-organic coordination can be controlled to direct layer-by-layer (LBL) assembly of thin films with sequential deposition of the organic and metal component on a functionalized surface, permitting atomic control of film structure and composition. These multilayer thin films are simple to fabricate as they do not require high energy or vacuum systems and they have been studied for applications in lithography, electronics, and photonics. ${ }^{14-22}$ This method of alternating, sequential solution-phase deposition has been implemented to attach MOFs directly to an underlying substrate. ${ }^{10-13,23-28}$ The structure of SurMOFs has been generally described as a scaffold containing metal ions as joints and organic molecules as the connecting beams defining pore size, shape, and composition. A simplistic mechanism for this structural LBL formation suggests pseudoepitaxial growth with the inorganic and organic component each deposited as a conformal, continuous film extending in two dimensions covering the entire underlying substrate consistent with a Van der Merwe growth mechanism. In this scenario, a layer of ions populates exposed underlying coordination sites, followed by a

Received: April 12, 2015

Revised: May 17, 2015

Published: May 18, 2015 
layer of organic molecules that bridge metal ion sites and protrude upward presenting an interface for subsequent metal ion binding. This is analogous to the architecture of metalorganic coordinated multilayer film systems, such as $\mathrm{Cu}^{2+}$ with $\alpha, \omega$-mercaptoalkanoic acid and $\mathrm{Zn}^{2+}$ with $\alpha, \omega$-bisphosphonic acid. $^{29,30}$ Spectroscopic measurements of SurMOF growth support this comparison as the observed signals increase in a linear fashion as a function of deposition cycles. ${ }^{23-25}$ However, the SurMOF growth mechanism has not been verified by nanoscale structure characterization using proximal probes.

Controlled stepwise assembly of the SurMOF film is used to design pores containing tailored functionalities within the framework. Also, this procedure permits MOF systems to be directly incorporated onto or into device architectures, sensor platforms, or other test-beds. Therefore, to fabricate these smart interfaces successfully, it is important to know the quality and structure of the connection formed by the foundational layers between the underlying substrate and porous framework. Basic understanding of how the initial layers of the SurMOF films form can lead to the ability to tailor the film's morphological properties, such as roughness, grain size, and thickness. This would, in effect, allow the material to be tuned for specific applications that may be improved by high surface roughness (e.g., increase rate of uptake or selectivity for gas adsorption $)^{31-33}$ or by large grain sizes with uniform thickness (e.g., low k-dielectric layer, photoelectrodes, and smart interfaces). ${ }^{10-13}$ Alternating, solution-phase deposition can be utilized to create a seed layer for subsequent film formation by codeposition of the two components. ${ }^{34}$ Understanding the nanoscale structure of the seed layer is important because the quality of that foundational layer impacts the final film structure.

This study examines the structure of the foundational layers of a SurMOF using scanning probe microscopy (SPM). Changes in surface morphology throughout layer deposition provide insight into film formation so that the growth mechanism can be determined to be Van der Merwe, Stranski-Krastanov, or Volmer-Weber. The HKUST-1 framework was selected because it is a benchmark system found throughout the literature as a powder and film, with studies demonstrating its performance for a wide range of applications. ${ }^{10-13,23-28,31-46}$ In situ SPM studies have observed HKUST-1 crystal growth where both the inorganic and organic components are present in solution. ${ }^{35,36}$ XRD studies have shown that preferred crystal orientation for the SurMOF is determined by the underlying chemical functionality of the substrate. ${ }^{37,38}$ Growth can be inhibited by the presence of certain functional groups, which has been exploited to permit selective deposition of the SurMOFs on chemically patterned substrates. ${ }^{39}$ SPM studies have investigated the thickness and morphology of HKUST-1 films grown on these patterned surfaces, specifically investigating films after ten plus layers have been deposited. ${ }^{39}$ Although thin films of HKUST-1 formed by greater than ten cycles of deposition have been characterized, SPM studies of the foundational layers have not been shown previously.

This research investigates the first ten foundational layers of the SurMOF revealing a heterogeneous surface structure. The sequence of images collected show that film growth begins with the nucleation of small isolated particles (MOF nanocrystallites) that increase in size with increasing deposition cycles, revealing a Volmer-Weber growth mechanism. These findings show that the growth mechanism for the HKUST-1 system differs greatly from that of metal-organic multilayers, which form continuous, conformal layers coating the underlying substrate and follow a Van der Merwe growth mechanism. ${ }^{14-22,29,30}$ Image analysis was conducted to determine surface roughness and surface coverage. Crystal orientation was elucidated based on high-resolution SPM. Processing variables, such as deposition temperature and substrate quality, were studied in order to understand how to optimize the structure for different applications. A thorough comparison of films deposited at 25 and $50{ }^{\circ} \mathrm{C}$ is described and data regarding the effect of substrate quality is presented. These fundamental studies of the SurMOF formation are critical for their successful incorporation into hierarchical architectures.

\section{MATERIALS AND METHODS}

Materials. Trimesic acid [TMA] (95\%) and 16-mercaptohexadecanoic acid [MHDA] (90\%) are from Aldrich (St. Louis, MO). Copper(II) acetate monohydrate was obtained from Fisher Scientific (Fair Lawn, NJ), and absolute, anhydrous ethanol (200 proof, ACS/ USP grade) was from Phamco-Aaper (Shelbyville, KY). All chemicals were used as received. Two types of gold substrates were obtained from Platypus Technologies (New Orleans, LA): (1) silicon wafers with 5-nm $\mathrm{Ti}$ adhesion layer and $100-\mathrm{nm} \mathrm{Au}$; (2) ultraflat template stripped 100-nm gold chips.

Methods. Sample Preparation. The HKUST-1 SurMOF film system was fabricated by the alternating solution-phase deposition of TMA and copper ions on a gold substrate functionalized with a selfassembled monolayer (SAM) of 16-mercaptohexadecanoic acid (MHDA), in accordance with established protocol. ${ }^{23}$ The gold substrate was first immersed in a $1 \mathrm{mM}$ MHDA ethanol solution for $1 \mathrm{~h}$. The substrate was then removed, rinsed thoroughly with ethanol, dried with nitrogen, and immediately submerged in a $1 \mathrm{mM}$ ethanol solution of copper acetate. The substrate was removed after $30 \mathrm{~min}$, rinsed with ethanol, dried with nitrogen, and submerged in a $0.1 \mathrm{mM}$ ethanol solution of TMA for $1 \mathrm{~h}$. The substrate was promptly removed, rinsed with ethanol, and dried with nitrogen. Then, a portion of the substrate was broken off and stored for characterization. This was routinely done after each deposition of the organic component. The remaining substrate was then immersed in a $1 \mathrm{mM}$ copper acetate solution to continue the deposition process. This alternating solutionphase deposition of copper ions and TMA was repeated for the desired number of deposition cycles. Each sample in a set was from the same piece of gold to ensure sample uniformity. Sample sets were fabricated with solutions held at either 25 or $50{ }^{\circ} \mathrm{C}$.

Scanning Probe Microscopy (SPM). Multiple images $(512 \times 512$ pixels) were obtained for each sample at $5 \mu \mathrm{m}$ and $500 \mathrm{~nm}$ using a Dimension Icon Atomic Force Microscope (Bruker, Santa Barbara, $\mathrm{CA}$ ), operating in peak force tapping mode. Etched silicon tips, SCANASYST-AIR (Bruker, Santa Barbara, CA), with a spring constant range of $0.2-0.8 \mathrm{~N} / \mathrm{m}$ and a resonant frequency range of $45-95 \mathrm{kHz}$ were used. Scan parameters were as follows: $1-\mathrm{Hz}$ scan rate, $12-\mu \mathrm{m} z$ range, $250-370-\mathrm{mV}$ amplitude set point, and $100-450-\mathrm{mV}$ drive amplitude. Basic image analysis was routinely undertaken using the Nanoscope Analysis software (Bruker, Santa Barbara, CA). This program was used to calculate the surface roughness, Rq. SPM data presented herein are representatitive of compiled data for multiple sample sets fabricated at either 25 or $50{ }^{\circ} \mathrm{C}$.

Image Analysis. Using the NanoScope Analysis software (Bruker), all $5-\mu \mathrm{m}$ images were plane fitted and the color scale was set uniformly to be $50 \mathrm{~nm}$. Then, these were quantitatively characterized using ImageJ (NIH online resource) processing software. ${ }^{47}$ Details regarding this process can be found in the Supporting Information (SI).

Ellipsometry. To investigate film growth, film thickness was characterized using a variable-angle discrete wavelength ellipsometer (PHE-101 VADE, Angstrom Advanced, Braintree, MA). Data were acquired for each sample collecting a minimum of three spots at a wavelength of $632.8 \mathrm{~nm}$ and a fixed angle of $70^{\circ}$. With the PHE-101 


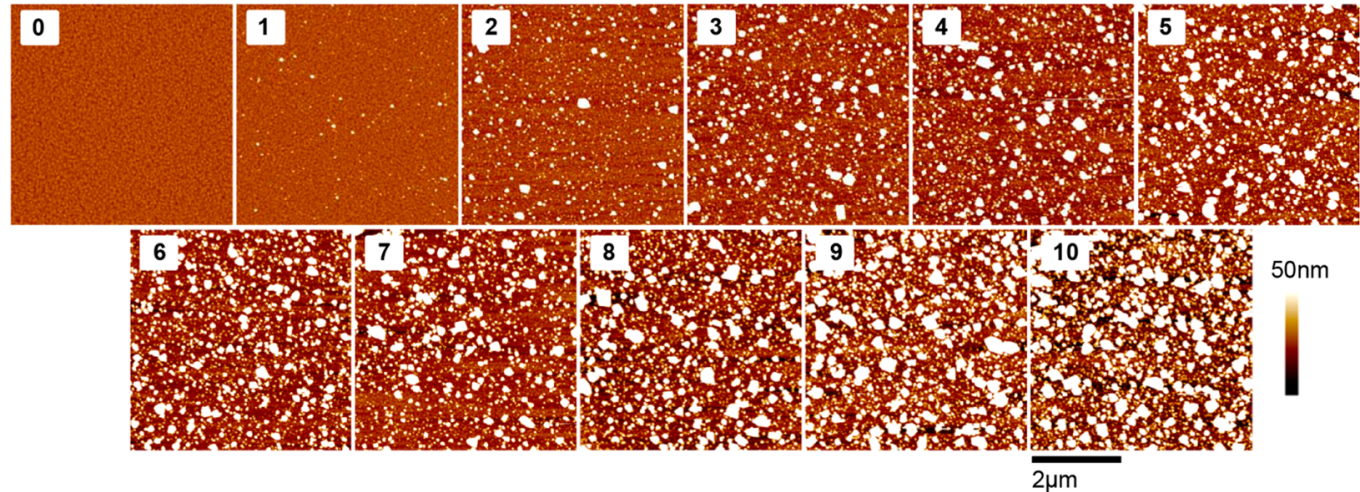

Figure 1. Representative SPM images $(5 \mu \mathrm{m} \times 5 \mu \mathrm{m})$ show SurMOF film growth after SAM deposition and throughout the first ten cycles of deposition for the HKUST-1 system at $25{ }^{\circ} \mathrm{C}$. Each image is labeled with the number of deposition cycles the sample had undergone when characterized. All images are set to the same $z$-scale $(50 \mathrm{~nm})$ for visual comparison and quantitative analysis of surface coverage.

analysis software, the film thickness was calculated using the refractive index values of $n=1.5$ and $k=0 .{ }^{29,40}$

\section{RESULTS AND DISCUSSION}

To investigate the bottom-up assembly of these MOF scaffolds on a surface, SPM characterization was undertaken throughout the deposition process. The nanoscale structure of these HKUST-1 films is examined herein and analyzed quantitatively to gain insight in the film formation mechanism. Data regarding surface roughness and surface coverage are presented in addition to the representative SPM images, revealing how the film forms as a function of deposition cycles and as a function of deposition temperature. As many previous studies have characterized these films via optical methods, ellipsometry data was collected for comparison and as a routine method to verify that film formation is occurring in a characteristic manner.

Scanning Probe Microscopy. SPM is key for characterizing this nanostructured material at an interface. Images of films fabricated at $25{ }^{\circ} \mathrm{C}$ are displayed in Figure 1. This series of images give a qualitative representation of the HKUST-1 thin film growth scheme. All images have been set to the same $z$ scale for direct comparison and for uniform characterization by image analysis. The sample composed of the SAM on the gold substrate (labeled 0 in Figure 1) is included to show the granular structure of the underlying gold substrate (roughness $=1.5 \mathrm{~nm}$ ). From the first to second deposition cycle, the number of particles on the surface is observed to increase significantly. Samples after subsequent deposition cycles have an increase in crystallite size, which ultimately leads to individual particles coalescing together (most apparent in images collected after 9 and 10 deposition cycles).

A subset of the samples represented in Figure 1 is shown in Figure 2 with higher resolution and set to a lower $z$-scale. This resolution was collected specifically to characterize the substrate regions between the MOF crystallites to investigate if changes were occurring on a smaller scale than apparent in the larger images. This was undertaken to determine if a conformal, continuous thin film forms in addition to the formation of the larger crystals as is observed for thin film formation that follows the Stranski-Krastanov growth mechanism. However, in Figure 2 , consistent structural characteristics are observed for all of the substrate regions. The gold substrate was thermally deposited and the small grains of gold $\sim 50 \mathrm{~nm}$ in diameter are seen in all samples. Also a consistent texture on the gold grains of the substrate is observed for all samples. The observed texture may

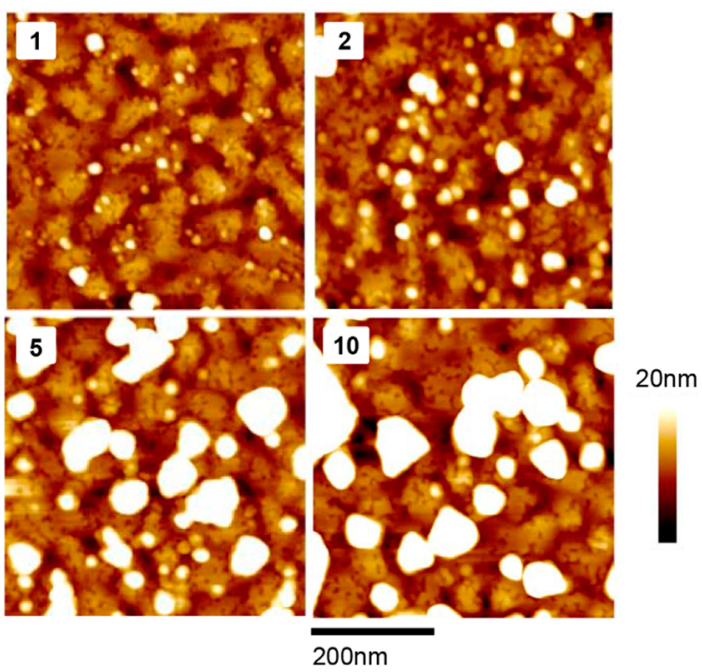

Figure 2. Representative SPM images $(500 \mathrm{~nm} \times 500 \mathrm{~nm})$ for a subset of the samples characterized after $1,2,5$, and 10 deposition cycles at $25^{\circ} \mathrm{C}$. These regions were selected specifically to characterize the area on the sample between the MOF crystallites in order to investigate possible changes occurring on a smaller scale than apparent in the larger images. All images are set to the same $z$-scale $(20 \mathrm{~nm})$, which is smaller than in Figure 1. This $z$-scale was chosen in order to visually render the small height changes in the substrate discernible. The background of all these images was observed to be uniform.

be areas of disorder in the SAM, regions of the SAM with a different tilt angle, or regions of the SAM covered with TMA after the previous exposure of the organic component. The lack of conformal film growth observed between the MOF islands confirmed that the growth mechanism was Volmer-Weber, indicating the adsorbate-adsorbate interaction is greater than the adsorbate-substrate interaction.

For the image collected after the initial deposition cycle, labeled as 1 in Figure 2, a large number of particulates, $\sim 10 \mathrm{~nm}$ in diameter, are observed to have nucleated across the substrate. A change is observed after the second deposition cycle, when slightly larger particles are observed in addition to more small particulates that are similar to those found after the first deposition cycle. Also noteworthy is that in the samples that underwent five and ten deposition cycles, there are still very tiny $(\sim 10 \mathrm{~nm})$ particulates. This suggests that either the nucleation of new particles is still continuing or the growth of the crystals is not uniform across the sample. It should be noted 


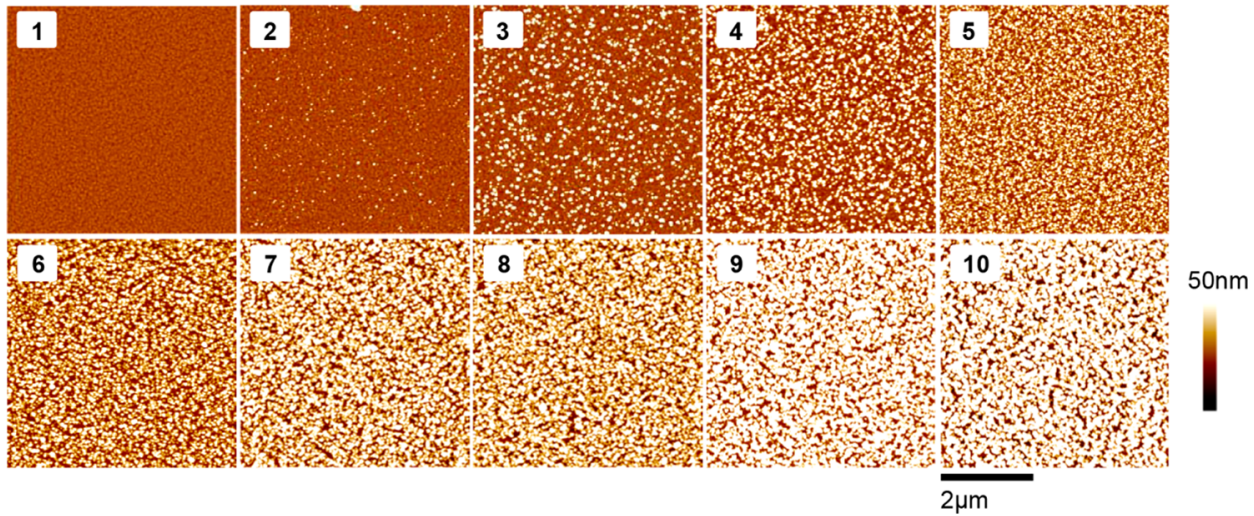

Figure 3. Representative SPM images $(5 \mu \mathrm{m} \times 5 \mu \mathrm{m})$ show SurMOF film growth throughout the first ten cycles of deposition for the HKUST-1 system at $50{ }^{\circ} \mathrm{C}$. Each image is labeled with the number of deposition cycles the sample had undergone when characterized. All images are set to the same $z$-scale $(50 \mathrm{~nm})$ for visual comparison and quantitative analysis of surface coverage.

that the 500-nm imaged regions were specifically selected from the $5-\mu \mathrm{m}$ images in order to obtain an image of the background substrate, so areas with fewer particles were selected. Therefore, these 500 -nm images are not necessarily representative of the average particle coverage.

A sequence of images is displayed in Figure 3 that is representative of films formed by solution-phase deposition at $50{ }^{\circ} \mathrm{C}$. For direct comparison to Figure 1, these images are the same dimensions and set to the same $z$-scale. In these samples fabricated at the elevated temperature, a Volmer-Weber growth mechanism is observed and yet the particles formed during the first few deposition cycles are smaller than those that appear in the $25{ }^{\circ} \mathrm{C}$. However, although the sizes of the particles in the samples fabricated at a higher temperature are smaller, the number of particles covering the substrate is significantly greater. The surface appears to be about half covered with particles after ten cycles of deposition at $25{ }^{\circ} \mathrm{C}$, yet the same number of deposition cycles at $50{ }^{\circ} \mathrm{C}$ yields a surface that is nearly fully covered by particles. It is also noteworthy that the same background substrate structure seen in Figure 2 for the $25{ }^{\circ} \mathrm{C}$ sample set was observed to be present in samples fabricated at $50{ }^{\circ} \mathrm{C}$ (see SI). Therefore, the increased number of nucleation sites observed at the higher temperature does not appear to be due to changes in the SAMfunctionalized surface induced by deposition at an elevated temperature.

Quantitative Image Analysis. Beyond the qualitative interpretation that can be gleaned from the SPM images, methods of quantitative analysis have been employed to determine surface roughness (Figure $4 \mathrm{a}$ ) and surface coverage (Figure $4 b$ ) as a function of deposition cycle. A numerical value for each of these properties was ascertained for each individual image. Results were compiled to determine the overall mean and associated standard deviation, which are plotted in Figure $4 \mathrm{a}$ and $4 \mathrm{~b}$. It was found that despite the layer-by-layer deposition method, a linear fit did not best represent this data. Therefore, for each property investigated, the change between each successive deposition layer was calculated and the average change will be presented.

Roughness ( $\mathrm{Rq}$ ) measurements are shown in Figure 4a. For $25^{\circ} \mathrm{C}$, the average increase in roughness per deposition cycle is $3.8 \mathrm{~nm}$ with the trend perhaps beginning to level off or even decrease at 10 cycles. For $50{ }^{\circ} \mathrm{C}$, the average increase in roughness for the first six deposition cycles is $2.4 \mathrm{~nm}$ per cycle, but the roughness remains relatively constant after that. For the
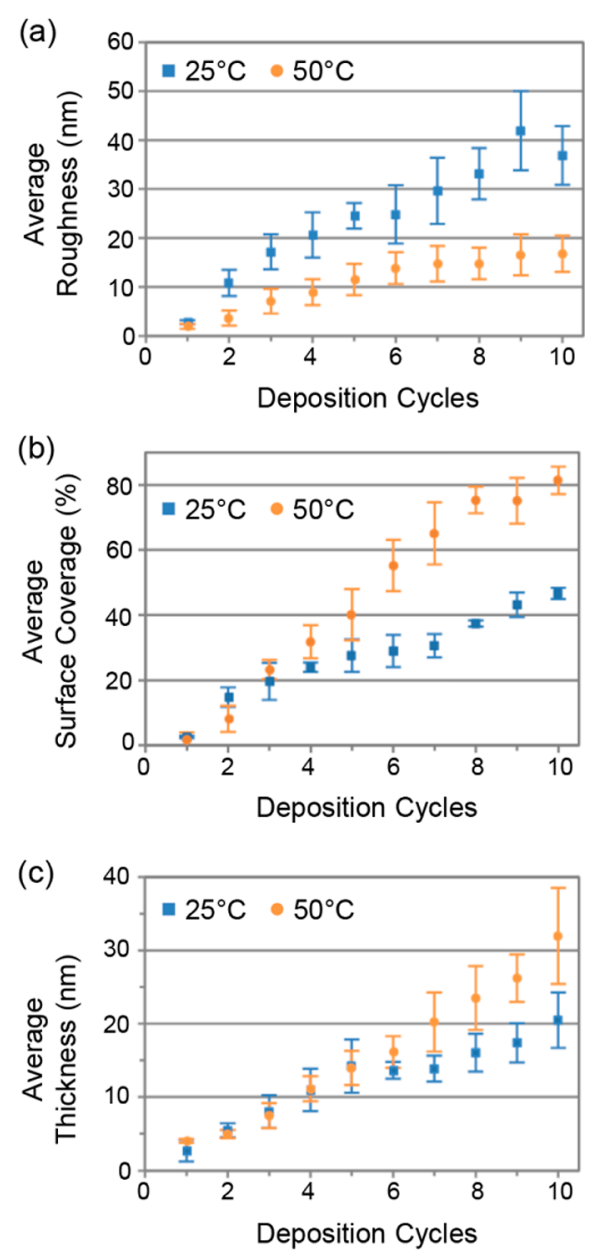

Figure 4. Surface roughness, Rq, (a) and surface coverage (b) determined for $5 \mu \mathrm{m} \times 5 \mu \mathrm{m}$ SPM images, like those shown in Figure 1 and 3 , are plotted as a function of deposition cycles. Film thickness (c), as determined by ellipsometry, is plotted relative to the number deposition cycles. Data for samples fabricated at $25^{\circ} \mathrm{C}$ (blue squares) and $50{ }^{\circ} \mathrm{C}$ (orange squares) are displayed in these graphs for comparison.

samples fabricated at $50{ }^{\circ} \mathrm{C}$, the average roughness of the samples is significantly lower at approximately half the roughness of the samples deposited at $25{ }^{\circ} \mathrm{C}$. It was verified that the roughness numbers from the $5 \mu \mathrm{m} \times 5 \mu \mathrm{m}$ images are 
consistent with those obtained for larger areas of the sample (representative images for larger dimensions are included in the SI along with associated $\mathrm{Rq}$ values).

On the basis of these results, it is important to consider a previously proposed layer-by-layer or Van der Merwe growth mechanism for this SurMOF system. ${ }^{23,26,37,38}$ In the LBL growth mechanism case, the deposition cycle would begin with a single layer of copper ions deposited on underlying carboxylic acids, displacing half their associated counter-anions. The remaining counter-anions would be displaced upon the addition of a molecular layer of the TMA, completing the cycle. This would create a continuous film extending uniformly across an underlying substrate, so a significant increase in film roughness would not be expected to occur and an overall homogeneous surface structure would be observed. Therefore, the crystallite nucleation and growth found to occur for this system at both temperatures does not follow the aforementioned layer-by-layer growth mechanism.

SPM images of particle nucleation and growth were analyzed quantitatively using the particle analysis applet of the image analysis software, Image J. ${ }^{47}$ The background of the image was subtracted to increase the contrast between the substrate and crystallites. Next, the image was thresholded to highlight all the particles on the surface. An outline of the particles was then generated, which determined the number of particles on the surface, the size of the particles, and the surface coverage (percent of the imaged region covered by particles). The data shown in Figure $4 \mathrm{~b}$ were obtained by this method (additional details provided in SI).

At both temperatures, as the number of particles decreases, the particle size and surface coverage (Figure $4 \mathrm{~b}$ ) increases. Data showed that with additional deposition cycles the nucleation of new particles decreased and existing crystallites continued to grow and collide with one another to cover the underlying substrate. Note that new tiny particles are present in the samples after five and ten deposition cycles (Figure 2), suggesting that nucleation of new particles may continue throughout the deposition cycles. However, the number of new nucleation events undoubtedly decreases as film surface coverage increases because the amount of accessible substrate has decreased. For perspective on the size of the particles throughout deposition, if the particles in the $25{ }^{\circ} \mathrm{C}$ sample set are assumed to be square, then the average side lengths for the 1,5 , and 10 cycle samples are 21,57 , and $107 \mathrm{~nm}$.

For samples fabricated at 25 and $50{ }^{\circ} \mathrm{C}$, a large increase in nucleation from one to two cycles occurred with the maximum number of distinct particles observed after two cycles at $25{ }^{\circ} \mathrm{C}$ and after three cycles at $50{ }^{\circ} \mathrm{C}$. This slower nucleation rate at the elevated temperature is shown in Figure $4 \mathrm{~b}$ with percent surface coverage at $50^{\circ} \mathrm{C}$ being lower than $25^{\circ} \mathrm{C}$ after the first two deposition cycles and comparable after the third deposition cycle. It is not until after the fourth deposition cycle that the surface coverage is higher for the samples fabricated at the higher temperature. Despite this slow start to crystal nucleation, crystal growth and associated surface coverage then occurs much faster for samples prepared at $50{ }^{\circ} \mathrm{C}$ versus $25{ }^{\circ} \mathrm{C}$.

An average increase in surface coverage per cycle is 4.9 and $8.9 \%$ for 25 and $50{ }^{\circ} \mathrm{C}$, respectively. Based on this, it is estimated that the substrate would be covered completely after 21 deposition cycles at $25^{\circ} \mathrm{C}$ or after 12 deposition cycles at 50 ${ }^{\circ} \mathrm{C}$. This is likely an underestimation of the number of cycles necessary because the change in surface coverage is not linear and, notably, the samples fabricated after ten deposition cycles have a slightly lower average surface coverage, $47 \%$ at $25{ }^{\circ} \mathrm{C}$ and $81 \%$ at $50{ }^{\circ} \mathrm{C}$, than would be estimated.

The samples fabricated at $25{ }^{\circ} \mathrm{C}$ exhibit lower surface coverage and higher roughness compared to samples fabricated at $50{ }^{\circ} \mathrm{C}$. This indicates a difference in the film growth occurring on the previously deposited MOF crystallites and on the SAM covered substrate. The lower surface coverage with the increased surface roughness of the $25{ }^{\circ} \mathrm{C}$ samples suggests preferential film growth vertically on previously deposited crystallites. Whereas the higher surface coverage and lower roughness of the $50{ }^{\circ} \mathrm{C}$ samples reveals potentially more lateral film growth on previously deposited crystallites and an increased preference for growth on the substrate relative to the $25{ }^{\circ} \mathrm{C}$ samples. To briefly summarize, film growth at $25{ }^{\circ} \mathrm{C}$ is more vertical and at $50{ }^{\circ} \mathrm{C}$ is more horizontal. This type of fundamental understanding is vital for those researchers who would desire to incorporate the film into a device structure.

Ellipsometry. For this study, ellipsometry was used routinely to verify that SurMOF film growth was occurring in a characteristic manner (Figure 4c). The refractive index and extinction coefficient was assumed to be 1.5 and 0 , respectively, which are commonly used for characterizing metal-organic coordinated multilayers. $^{29}$ These values correspond well with those recently found for thin, smooth films of the HKUST-1 system, with a thickness of $\sim 100 \mathrm{~nm}$, fabricated by 40 spray deposition cycles. ${ }^{40}$ In the study herein, the average change in thickness per cycle is estimated to be 2.0 and $3.1 \mathrm{~nm}$ for 25 and $50{ }^{\circ} \mathrm{C}$, respectively. Considering this alongside the surface coverage, continuous films completely covering the substrate would be $42-\mathrm{nm}$ thick after 21 deposition cycles at $25^{\circ} \mathrm{C}$ and $37-\mathrm{nm}$ thick after 12 deposition cycles at $50{ }^{\circ} \mathrm{C}$.

One of the general assumptions made for the fitting of ellipsometry data is that the film is homogeneous, which is not the case as observed by SPM. Therefore, the changes in thickness found here by ellipsometry are an average of the thickness of the particulates spread out across the region of the substrate sampled by the $1-\mathrm{mm}$ spot size of the ellipsometer laser. This data demonstrates the limitation of this method to characterize ultrathin film formation, elucidating the need for proximal probes to investigate the nanoscale structure of these films. It is noteworthy that the general trend for the surface coverage determined by image analysis (Figure $4 \mathrm{~b}$ ) and the average thickness determined by ellipsometry (Figure 4c) are in agreement. This supports the description of the ellipsometry data as representing the average thickness of the particulates within the $\sim 1-\mathrm{mm}$ region that the laser beam is sampling on the surface.

Investigating Effect of Processing Conditions on Film Formation. Deposition temperatures investigated herein are shown to significantly affect the SurMOF film formation. At the elevated temperature, the average change in surface coverage per deposition cycle is higher and the film roughness throughout deposition is significantly decreased. The chosen $z$-scale in Figure 1 and Figure 3 is selected to clearly compare the number of particles, the particle area, and the surface coverage. However, from this presentation of the data, the three-dimensional shape of the particles cannot be appreciated. In Figure 5, three-dimensional renderings of SPM images are displayed to represent the differences in the crystallite structures that are predominately found for samples fabricated at $25{ }^{\circ} \mathrm{C}$ versus $50{ }^{\circ} \mathrm{C}$. These images are from samples fabricated by three deposition cycles. For deposition at $25^{\circ} \mathrm{C}$, square pyramidal crystallites are primarily observed (hence why 
(a)

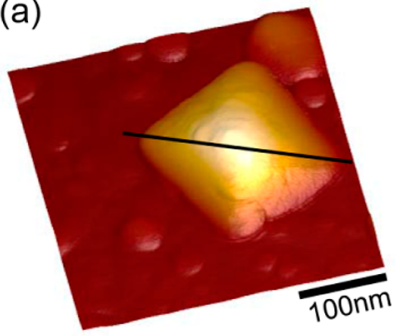

(c)

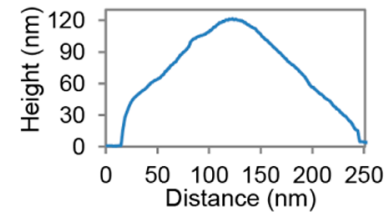

(b)

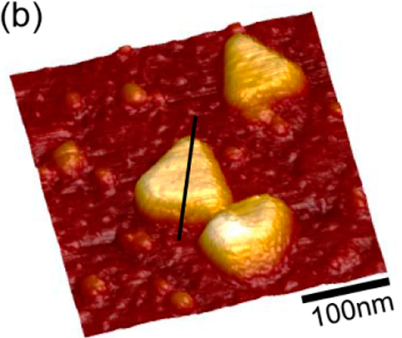

(d)

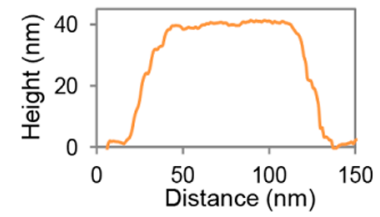

Figure 5. Three-dimensional renderings of SPM images $(350 \mathrm{~nm} \times$ $350 \mathrm{~nm}$ ) for samples characterized after 3 deposition cycles at $25^{\circ} \mathrm{C}$ (a) and $50{ }^{\circ} \mathrm{C}(\mathrm{b})$. Line profiles, represented by the black lines in the SPM images, are shown below (c, d). The crystallite on the $25{ }^{\circ} \mathrm{C}$ sample (a, c) is square pyramidal with a height of $122 \mathrm{~nm}$, while the crystallite on the $50{ }^{\circ} \mathrm{C}$ sample $(\mathrm{b}, \mathrm{d})$ is trigonal planar with a height of $39.8 \mathrm{~nm}$.

when particle size is approximated earlier, a square base is supposed). The height of the pyramid found for the SurMOF deposited at $25^{\circ} \mathrm{C}$ is $122 \mathrm{~nm}$, as determined by the maximum of the line profile shown in Figure 5c. After deposition at elevated temperatures, the surface is covered with trigonal planar crystallites. The line profile for this crystallite, Figure $5 \mathrm{~d}$, on the sample fabricated at $50{ }^{\circ} \mathrm{C}$ has an average maximum height of $39.8 \mathrm{~nm}$.

Differences in roughness and surface coverage can be understood based on these differences in crystal growth. The high roughness found at $25{ }^{\circ} \mathrm{C}$ is due to these tall pyramidal structures that are forming during deposition cycles. The high surface coverage for the samples fabricated at elevated temperatures is due to the trigonal planar crystallites that are growing more laterally compared to vertically. The observance of pyramids is indicative of crystal growth along the [100], which is consistent with literature for carboxylic acid terminated SAMs (used in this study). ${ }^{23,25,26,37,38}$ Observance of triangular islands is the crystal growth oriented along the [111], which has been previously shown to be the case for hydroxyl terminated SAMs. ${ }^{23,25,26,37,38}$ It is noteworthy that this [111] crystal face in the bulk HKUST-1 structure has a high density of hydroxyl groups. ${ }^{23}$ Whereas no significant change in the SAM background was observed at $50{ }^{\circ} \mathrm{C}$ (see SI), it could be hypothesized that the increased temperature for deposition affected the orientation or packing of the pendant carboxylic acids on the SAM, inducing crystal growth along a different crystal face. It is also probable that the growth of this crystal face requires higher energy that is facilitated by deposition at elevated temperatures.

Additional research has been undertaken to characterize the HKUST-1 SurMOF thin film formed on atomically smooth gold substrates and to examine film growth after the copper deposition. The effect of the substrate has been investigated to determine if the grain boundaries present in the thermally deposited gold either created the nucleation sites or prevented continuous layer formation (Figure 6). The roughness, thickness, and surface coverage obtained for these samples are all in agreement with the data shown for the $25{ }^{\circ} \mathrm{C}$ sample
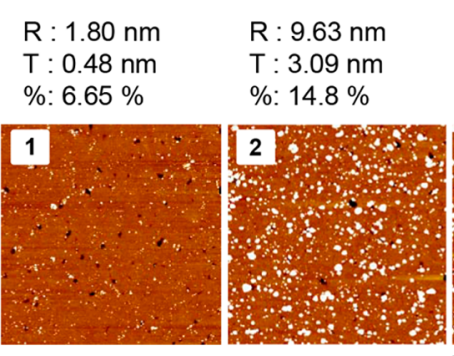

$\mathrm{R}: 19.3 \mathrm{~nm}$

$\mathrm{T}: 6.22 \mathrm{~nm}$

$\%: 20.5 \%$

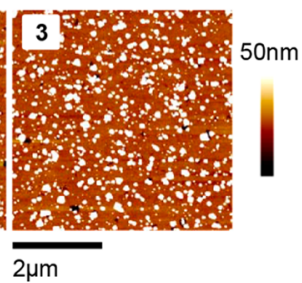

Figure 6. Representative SPM images $(5 \mu \mathrm{m} \times 5 \mu \mathrm{m})$ show crystallite growth during the first three cycles of deposition for the HKUST-1 system $25^{\circ} \mathrm{C}$ on template stripped, atomically smooth $\mathrm{Au}$. Each image is labeled with the number of deposition cycles the sample had undergone when characterized. Data regarding roughness (R), film thickness as measured by ellipsometry (T), and surface coverage (\%) are given for comparison to data in Figure 4. All images are set to the same $z$-scale $(50 \mathrm{~nm})$.

in Figure 4. The same observations found herein for particle count, size, coverage, and roughness were also found for SurMOF films deposited by liquid-phase epitaxy on atomically flat gold fabricated by template stripping. This shows that the film formation is unaffected by the large number of grain boundaries consistent with gold films formed by thermal metal evaporation. Although all the data shown herein were obtained after the organic component was deposited, preliminary studies have shown the same structures and surface morphologies are present after the metal ion is deposited. Results from quantitative image analysis of those samples fit well within the average trends, suggesting that some degree of growth may occur after deposition of each component.

\section{CONCLUSIONS}

For the successful incorporation of SurMOFs into technological applications, further research is crucial to investigate the effect of the substrate (i.e., composition, structure) and processing variables (i.e., concentration, time, solvent, temperature) on morphological structure. Scanning probe microscopy studies are important for characterizing the nanostructured features of this material at an interface. To support these studies, further work utilizing advanced X-ray scattering techniques will investigate the crystallinity of these ultrathin films. Research exploring the formation of SurMOFs with different compositions is underway to determine how and why these trends are similar or different when compared to other metal-organic coordinated systems. This research yields insight into film formation throughout the solution-phase deposition process enabling future investigation of processing variables to tailor the structure, such as catalytic inclusions and postsynthetic modification.

Alternating solution-phase deposition of the HKUST-1 system resulted in a crystallite-rich substrate with surface coverage and film thickness increasing with the number of deposition cycles. To the authors' knowledge, this is the first scanning probe microscopy (SPM) study to systematically and quantitatively investigate the formation of foundational layers (1-10) for a SurMOF fabricated via alternating solution-phase deposition. The findings show that the often-accepted conformal structure resulting from the Van der Merwe growth mechanism is incorrect for the foundational layers of the HKUST-1 system. Instead, the foundational layers of the film form following a Volmer-Weber growth mechanism. Image 
analysis investigated trends in how these MOF crystallites formed and grew, yielding quantitative information about surface roughness and surface coverage. Alteration of the standard processing conditions by increasing deposition temperature has proven to accelerate surface coverage, induce a change in crystal orientation, and reduce surface roughness. Results from this study predict that complete coverage of the substrate would not occur until after 21 deposition cycles at 25 ${ }^{\circ} \mathrm{C}$ and after 12 deposition cycles at $50{ }^{\circ} \mathrm{C}$. These films would be 42 and $37 \mathrm{~nm}$ thick, respectively. The substrate quality was determined to not affect the film formation. Toward the goal of incorporating metal-organic coordinated assemblies as smart interfaces for sensing and photonic applications, this research is imperative on the road to the development of low-energy processing techniques to tailor structure and composition throughout the assembly process.

\section{ASSOCIATED CONTENT}

\section{S Supporting Information}

Representative image data set $(500 \mathrm{~nm} \times 500 \mathrm{~nm})$ for samples deposited at $50{ }^{\circ} \mathrm{C}$; images collected at dimensions larger than the $5 \mu \mathrm{m} \times 5 \mu \mathrm{m}$ size that is routinely used for analysis for comparison; details regarding the image analysis procedure. The Supporting Information is available free of charge on the ACS Publications website at DOI: 10.1021/acs.langmuir.5b01333.

\section{AUTHOR INFORMATION}

\section{Corresponding Author}

* E-mail: meanderson@hope.edu.

\section{Notes}

The authors declare no competing financial interest.

\section{ACKNOWLEDGMENTS}

We acknowledge funding from ACS-PRF (54106-UNI5) and NSF (MRI-1126462). Additional funding was provided by the Arnold and Mabel Beckman Foundation Scholars Program (M.L.O.), the Towsley Foundation (M.E.A.), and Hope College. We thank Prof. Jennifer Hampton for technical assistance.

\section{REFERENCES}

(1) Furukawa, H.; Cordova, K. E.; O’Keeffe, M.; Yaghi, O. M. The Chemistry and Applications of Metal-Organic Frameworks. Science 2013, 341, 1230444.

(2) Zhou, H.-C.; Kitagawa, S. Metal-Organic Frameworks (MOFs). Chem. Soc. Rev. 2014, 43, 5415-5418.

(3) Hu, Z.; Deibert, B. J.; Li, J. Luminescent Metal-Organic Frameworks for Chemical Sensing and Explosive Detection. Chem. Soc. Rev. 2014, 43, 5815-5840.

(4) Kreno, L. E.; Leong, K.; Farha, O. K.; Allendorf, M.; Van Duyne, R. P.; Hupp, J. T. Metal-Organic Framework Materials as Chemical Sensors. Chem. Rev. 2012, 112, 1105-1125.

(5) Dhakshinamoorthy, A.; Garcia, H. Metal-Organic Frameworks as Solid Catalysts for the Synthesis of Nitrogen-Containing Heterocycles. Chem. Soc. Rev. 2014, 43, 5750-5765.

(6) Yoon, M.; Srirambalaji, R.; Kim, K. Homochiral Metal-Organic Frameworks for Asymmetric Heterogeneous Catalysis. Chem. Rev. 2012, 112, 1196-1231.

(7) He, Y.; Zhou, W.; Qian, G.; Chen, B. Methane Storage in MetalOrganic Frameworks. Chem. Soc. Rev. 2014, 43, 5657-5678.

(8) Sumida, K.; Rogow, D. L.; Mason, J. A.; McDonald, T. M.; Bloch, E. D.; Herm, Z. R.; Bae, T.-H.; Long, J. R. Carbon Dioxide Capture in Metal-Organic Frameworks. Chem. Rev. 2012, 112, 724-781.
(9) Meek, S. T.; Greathouse, J. A.; Allendorf, M. D. Metal-Organic Frameworks: A Rapidly Growing Class of Versatile Nanoporous Materials. Adv. Mater. 2011, 23, 249-267.

(10) Eslava, S.; Zhang, L.; Esconjauregui, S.; Yang, J.; Vanstreels, K.; Baklanov, M. R.; Saiz, E. Metal-Organic Framework ZIF-8 Films As Low-k Dielectrics in Microelectronics. Chem. Mater. 2013, 25, 27-33.

(11) Joyce, J. T.; Laffir, R. R.; Silien, C. Layer-by-Layer Growth and Photocurrent Generation in Metal-Organic Coordination Films. J. Phys.Chem. C 2013, 117, 12502-12509.

(12) Heinke, L.; Cakici, M.; Dommaschk, M.; Grosjean, S.; Herges, R.; Bräse, S.; Wöll, C. Photoswitching in Two-Component SurfaceMounted Metal-Organic Frameworks: Optically Triggered Release from a Molecular Container. ACS Nano 2014, 8, 1463-1467.

(13) Falcaro, P.; Ricco, R.; Doherty, C. M.; Liang, K.; Hill, A. J.; Styles, M. J. MOF Positioning Technology and Device Fabrication. Chem. Soc. Rev. 2014, 43, 5513-5560.

(14) Walker, A. V. Building Robust and Reliable Molecular Constructs: Patterning, Metallic Contacts, and Layer-by-Layer Assembly. Langmuir 2010, 26, 13778-13785.

(15) Hatzor, A.; Weiss, P. S. Molecular Rulers for Scaling Down Nanostructures. Science 2001, 291, 1019-1020.

(16) Anderson, M. E.; Tan, L. P.; Mihok, M.; Tanaka, H.; Horn, M. W.; McCarty, G. S.; Weiss, P. S. Hybrid Approaches to Nanolithography: Photolithographic Structures with Precise, Controllable Nanometer-Scale Spacings Created by Molecular Rulers. Adv. Mater. 2006, 18, 1020-1022.

(17) Srinivasan, C.; Anderson, M. E.; Jayaraman, R.; Weiss, P. S.; Horn, M. W. Electrically Isolated Nanostructures Fabricated Using Self-Assembled Multilayers and a Novel Negative-Tone Bi-Layer Resist Stack. Microelectron. Eng. 2006, 83, 1517-1520.

(18) Hong, H.-G.; Mallouk, T. E. Electrochemical Measurements of Electron Transfer Rates through Zirconium 1,2-Ethanediylbis(phosphonate) Multilayer Films on Gold Electrodes. Langmuir 1991, 7, 2362-2369.

(19) Katz, H. E.; Schilling, M. L. Electrical Properties of Multilayers Based on Zirconium Phosphate/Phosphonate Bonds. Chem. Mater. 1993, 5, 1162-1166.

(20) Altman, M.; Shukla, A. D.; Zubkov, T.; Evmenenko, G.; Dutta, P.; van der Boom, M. E. Controlling Structure from the Bottom-Up: Structural and Optical Properties of Layer-by-Layer Assembled Palladium Coordination-Based Multilayers. J. Am. Chem. Soc. 2006, 128, 7374-7382.

(21) Neff, G. A.; Helfrich, M. R.; Clifton, M. C.; Page, C. J. Layer-byLayer Growth of Acentric Multilayers of $\mathrm{Zr}$ and Azobenzene Bis(phosphonate): Structure, Composition, and Second-Order Nonlinear Optical Properties. Chem. Mater. 2000, 12, 2363-2371.

(22) Brust, M.; Blass, P. M.; Bard, A. J. Self-Assembly of Photoluminescent Copper(I)-Dithiol Multilayer Thin Films and Bulk Materials. Langmuir 1997, 13, 5602-5607.

(23) Shekhah, O.; Wang, W.; Zacher, D.; Fischer, R. A.; Wöll, C. Growth Mechanism of Metal-Organic Frameworks: Insight into the Nucleation by Employing a Step-by-Step Route. Angew. Chem., Int. Ed. 2009, 48, 5038-5041.

(24) Shekhah, O.; Wang, H.; Kowarik, S.; Schreiber, F.; Paulus, M.; Tolan, M.; Sternemann, F.; Evers, C.; Zacher, D.; Fischer, R. A.; Wöll, C. Step-by-Step Route for the Synthesis of Metal-Organic Frameworks. J. Am. Chem. Soc. 2007, 129, 15118-15119.

(25) Shekhah, O.; Wang, H.; Strunskus, T.; Cyganik, P.; Zacher, D.; Fischer, R.; Wöll, C. Layer-by-Layer Growth of Oriented Metal Organic Polymers on a Functionalized Organic Surface. Langmuir 2007, 23, 7440-7442.

(26) Zacher, D.; Schmid, R.; Wöll, C.; Fisher, R. A. Surface Chemistry of Metal-Organic Frameworks at a Liquid-Solid Interface. Angew. Chem., Int. Ed. 2011, 50, 176-199.

(27) Bétard, A.; Fischer, R. A. Metal-Organic Frameworks Thin Films: From Fundamentals to Applications. Chem. Rev. 2012, 112, 1055-1083. 
(28) Stock, N.; Biswas, S. Synthesis of Metal-Organic Frameworks (MOFs): Routes to Various MOF Topologies, Morphologies, and Composites. Chem. Rev. 2012, 112, 933-969.

(29) Evans, S. D.; Ulman, A.; Goppert-Berarducci, K. E.; Gerenser, L. J. Self-Assembled Multilayers of $\omega$-Mercaptoalkanoic Acids: Selective Ionic Interactions. J. Am. Chem. Soc. 1991, 113, 5866-5868.

(30) Yang, H. C.; Aoki, K.; Hong, H.-G.; Sackett, D. D.; Arendt, M. F.; Yau, S.-L.; Bell, C. M.; Mallouk, T. E. Growth and Characterization of Metal(II) Alkanebisphosphonate Multilayer Thin Films on Gold Surfaces. J. Am. Chem. Soc. 1993, 115, 11855-11862.

(31) Peralta, D.; Chaplais, G.; Simon-Masseron, A.; Barthelet, K.; Pirngruber, G. D. Metal-Organic Framework Materials for Desulfurization by Adsoption. Energy Fuels 2012, 26, 4953-4960.

(32) Qian, D.; Lei, C.; Hao, G.-P.; Li, W.-C.; Lu, A.-H. Synthesis of Hierarchical Porous Carbon Monoliths with Incorporated MetalOrganic Frameworks for Enhancing Volumetric Based $\mathrm{CO}_{2}$ Capture Capability. ACS Appl. Mater. Interfaces 2012, 4, 6125-6132.

(33) Xiang, S.; Zhou, W.; Gallegos, J. M.; Liu, Y.; Chen, B. Exceptionally High Acetylene Uptake in Microporous Metal-Organic Framwork with Open Metal Sites. J. Am. Chem. Soc. 2009, 131, 12415-12419.

(34) Nan, J.; Dong, X.; Wang, W.; Jin, W.; Xu, N. Step-by-Step Seeding Prodcedure for Preparing HKUST-1 Membrane on Porous $\alpha$ Alumina Support. Langmuir 2011, 27, 4309-4312.

(35) Shoaee, M.; Anderson, M. W.; Attfield, M. P. Crystal Growth of the Nanoporous Metal-Organic Framework HKUST-1 Revealed by In Situ Atomic Force Microscopy. Angew. Chem., Int. Ed. 2008, 47, 85258528 .

(36) John, N. S.; Scherb, C.; Shoaee, M.; Anderson, M. W.; Attfield, M. P.; Bein, T. Single Layer Growth of Sub-Micron Metal-Organic Framework Crytals Observed by In Situ Atomic Force Microscopy. Chem. Commun. 2009, 41, 6294-6296.

(37) Biemmi, E.; Scherb, C.; Bein, T. Oriented Growth of the Metal Organic Framework $\mathrm{Cu}_{3}(\mathrm{BTC})_{2}\left(\mathrm{H}_{2} \mathrm{O}\right)_{3} \cdot x \mathrm{H}_{2} \mathrm{O}$ Tunable with Functionalized Self-Assembled Monolayers. J. Am. Chem. Soc. 2007, 129, 8054-8055.

(38) Liu, J.; Shekhah, O.; Stammer, X.; Arslan, H. K.; Liu, B.; Schüpbach, B.; Terfort, A.; Wöll, C. Deposition of Metal-Organic Frameworks by Liquid-Phase Epitaxy: The Influence of Substrate Functional Group Density on Film Orientation. Materials 2012, 5, $1581-1592$.

(39) Munuera, C.; Shekhah, O.; Wang, H.; Wöll, C. The Controlled Growth of Oriented Metal-Organic Frameworks on Functionalized Surfaces as Followed by Scanning Force Microscopy. Phys. Chem. Chem. Phys. 2008, 10, 7257-7261.

(40) Redel, E.; Wang, Z.; Walheim, S.; Liu, J.; Gliemann, H.; Wöll, C. On the dielectric and optical properties of surface-anchored metal organic frameworks: A study on epitaxially grown thin films. Appl. Phys. Lett. 2013, 103, 0919031-0919035.

(41) Chui, S. S.-Y.; Lo, S. M.-F.; Charmant, J. P.; Orpen, A. G.; Williams, I. D. A Chemcially Functionalizable Nanoporous Material $\left[\mathrm{Cu}_{3}(\mathrm{TMA})_{2}\left(\mathrm{H}_{2} \mathrm{O}\right)_{3}\right]_{\mathrm{n}}$. Science 1999, 283, 1148-1150.

(42) Majano, G.; Pérez-Ramírez, J. Scalable Room-Temperature Conversion of Copper(II) Hydroxide into HKUST-1 $\left(\mathrm{Cu}_{3}(\mathrm{btc})_{2}\right)$. Adv. Mater. 2013, 25, 1052-1057.

(43) Wu, D.; Guo, Z.; Yin, X.; Pang, Q.; Tu, B.; Zhang, L.; Wang, Y.G.; Li, Q. Metal-Organic Frameworks as Cathode Materials for $\mathrm{Li}^{-\mathrm{O}_{2}}$ Batteries. Adv. Mater. 2014, 26, 3258-3262.

(44) Jeong, N. C.; Samanta, B.; Lee, C. Y.; Farha, O. K.; Hupp, J. T. Coordination-Chemistry Control of Proton Conductivity in the Ionic Metal-Organic Framework HKUST-1. J. Am. Chem. Soc. 2012, 134, $51-54$.

(45) Abedi, S.; Morsali, A. Ordered Mesoporous Metal-Organic Frameworks Incorporated with Amorphous $\mathrm{TiO}_{2}$ As Photocatalyst for Selective Aeorobic Oxidation in Sunlight Irradiation. ACS Catal. 2014, 4, 1398-1403.

(46) Davydovskaya, P.; Ranft, A.; Lotsch, B. V.; Pohle, R. Analyte Detection with Cu-BTC Metal-Organic Framework Thin Films by means of Mass-Senitive and Work-Function-Based Readout. Anal. Chem. 2014, 86, 6948-6958.

(47) Image J. Image Processing and Analysis in Java; http://imagej.nih. gov/ij/. 